\title{
How carbon nanotubes affect the cure kinetics and glass transition temperature of their epoxy composites? - A review
}

\author{
A. Allaoui, N. El Bounia* \\ IPREM-CANBIO, CNRS UMR 5254, Université de Pau et des Pays de l’Adour, Pau, France
}

Received 6 May 2009; accepted in revised form 26 June 2009

\begin{abstract}
Motivated by the widespread and contradictory results regarding the glass transition temperature of carbon nanotube (CNT)/epoxy composites, we reviewed and analyzed the literature results dealing with the effect of unmodified multiwall carbon nanotubes (MWNT) on the cure behaviour of an epoxy resin (as a possible source of this discrepancy). The aim of this work was to clarify the effective role of unmodified multiwall carbon nanotubes on the cure kinetics and glass transition temperature $\left(T_{g}\right)$ of their epoxy composites. It was found that various authors reported an acceleration effect of CNT. The cure reaction was promoted in its early stage which may be due to the catalyst particles present in the CNT raw material. While SWNT may lead to a decrease of $T_{g}$ due to their bundling tendency, results reported for MWNT suggested an increased or unchanged $T_{g}$ of the composites. The present status of the literature does not allow to isolate the effect of MWNT on the $T_{g}$ due to the lack of a study providing essential information such as CNT purity, glass transition temperature along with the corresponding cure degree.
\end{abstract}

Keywords: nanocomposites, carbon nanotubes, cure kinetics, glass transition temperature

\section{Introduction}

The use of carbon nanotubes (CNT) as nanofillers in polymer matrices is one of their most promising applications, especially regarding epoxy resin. Multiple enhanced properties at low loadings are the major advantage of CNT over other fillers. Thanks to its good mechanical properties, chemical resistance and thermal stability, epoxy resin is a widely used polymer as adhesive, coating or as matrix in structural composites. The choice of a given application for epoxy is often based on the glass transition temperature, noted as $T_{g}$. This is the temperature at which the mechanical properties of a polymer drop and corresponds to a second-order phase transition at which the polymer goes from a glassy to a rubbery behaviour as the temperature increases. The $T_{g}$ is closely linked to the thermomechanical stability, it is thus the property that dictates the potential application of a given epoxy resin as a function of the service temperature range envisioned. In the case of epoxy resin, the $T_{g}$ is a function of the molecular architecture and depends on different parameter such as the functionality of the epoxy and of the hardener, the conversion degree, the curing cycle, etc. Due to the close relation between cure behaviour, glass transition temperature, mechanical properties and potential application of an epoxy resin, it is primordial to study the effect of CNT on the cure behaviour of the epoxy resin matrix. 


\section{Cure kinetics}

In the literature, different works were dedicated to the determination of the effect of CNT on the cure kinetics of an epoxy resin. Puglia et al. [1] claimed an acceleration effect of single wall carbon nanotubes (SWNT) on the cure reaction of the DGEBA/DETA epoxy system studied with dynamic and isothermal DSC. In that work, the decrease of the peak temperature (that is the temperature at the heat flow peak) in dynamic scans and the decrease of the time at heat flow peak in isothermal scans were taken as the proof of the acceleration in the early stage of the cure process. The presence of amine functional groups $\left(-\mathrm{NH}_{2}\right)$ on the surface of the SWNT that may react with the epoxy ring was the origin of the modification of the cure behaviour as shown in a paper from the same group presenting additional data on the same samples [2]. Xie et al. [3] also reported an acceleration effect in the case of multiwall carbon nanotubes (MWNT) for the TGDDM/DDS epoxy system using isothermal DSC. The higher initial reaction rate of the composites compared to the unfilled resin, the decrease of the time at maximum reaction rate and of the activation energy with increasing MWNT content were the indication of the acceleration effect. Evidence of the presence of hydroxyl groups $(-\mathrm{OH})$ on the surface of the MWNT by FTIR spectroscopy which have a catalytic effect on epoxy ring opening was in that case the source of the modified cure. The last stage of the cure remained unaffected by MWNT. The same group reported [4] on the effect of carbon nanofibres (CNF) on the cure behaviour of the same epoxy system. They found a very small acceleration effect of CNF in the early stage of the reaction suggested by the decrease of the activation energy with an increase of the $\mathrm{CNF}$ content. On the other hand, the CNF hinders the reaction after that step. Tao et al. [5] studied the effect of SWNT in the DGEBF/ DETD epoxy system and observed a decrease of the onset temperature in dynamic scans and a decrease of the time at maximum reaction in isothermal scans. Contrary to previous studies, they found that the peak temperature remained unaffected by the presence of SWNT. The origin of the acceleration effect cannot be clearly determined in their work due to the absence of surface characterization of the SWNT material. The high percentage of catalyst particles in the SWNT raw material may be a plausible source of the early cure initiation. In these investigations [1-5], it is believed that the modification of the cure behaviour in its early stage can be attributed to surface functional groups on CNT or catalyst particles. Wu et al. [6] studied the effect of three different carbon fillers (carbon fiber, carbon nanofiber and carbon black) on the cure reaction of the DGEBF/TETA epoxy system. They reported an increase of the total heat of reaction and a decrease of the temperature at the heat flow peak for all fillers. By comparing the effect of different pre-treatments of the carbon fibers, they explained the increase in the total heat of reaction as a result of the presence of surface functional groups on the fillers. The authors found that the acceleration effect, that is the decrease of the peak temperature, was closely related to the specific surface area (SSA) of the filler, in view of the proportionality between the SSA and the peak temperature drop (the higher the SSA, the higher the temperature drop). It should be noted that in that work, the fillers were manually dispersed in the resin and the filler content was high (around $20 \mathrm{wt} \%$ ). The authors did not give indication on the dispersion state of the fillers. Their samples may not have been homogeneous at the micro-scale and should have mainly contained aggregates of the filler, especially in the case of CNF which are highly entangled and stick to each other by van der Waals interactions. Bae et al. [7] investigated the effect of $\mathrm{CNT}$ and carbon black $(\mathrm{CB})$ on the cure reaction of liquid crystalline epoxy (DGE-DHAMS/sulfanilamide). In contradiction with all other studies, these authors reported a retardation effect of CNT, indicated by the slight increase of the temperature at maximum reaction. In their study, the presence of CNT did not have a significant effect on the total heat of reaction (except the expected decrease due to the lower weight fraction of epoxy in the composite) nor on the activation energy compared to unfilled epoxy. The authors noted that $\Delta \mathrm{H}_{0}$ was higher with CNT than with $\mathrm{CB}$. The oxidation treatment decreased the activation energy in both cases.

\section{Glass transition temperature}

Regarding the $T_{g}$, the data of Puglia et al. [1] revealed higher curing degree of the composites compared to unfilled resin which may correspond 
to a higher $T_{g}$. The $T_{g}$ was not measured in their work. Similarly, Xie et al. [3] did not measure the $T_{g}$ of their samples but their data revealed a higher curing degree of the composites for curing temperatures below $200^{\circ} \mathrm{C}$. For higher curing temperatures, the curing degree of the epoxy was higher. The same group [4] found that CNF did not have any effect on the final curing degree. Tao et al. [5] measured the $T_{g}$ of their samples after 2, 5 and 24 hours of isothermal curing and found that the $T_{g}$ of the composites was always lower than the unfilled epoxy. They attributed this to the lower curing degree of the composites as indicated by their lower isothermal heat of reaction but the curing degree was not explicitly calculated.

The literature dedicated to CNT/epoxy composites is extremely prolific. Given the importance of the glass transition temperature in view of its link with mechanical properties, it is amazing to see that even the last publications on the subject still do not always provide this information. In the case of mechanical properties, for comparison purpose, it is primordial to have the $T_{g}$ provided along with the curing degree of the samples. Most of the studies only claimed complete cure of the samples without further investigation. An analysis of the results from the literature dedicated to unmodified CNT in epoxy should lead to valuable conclusions. Any variations in the $T_{g}$ may be explained by some size effect or physical interactions with polymer chains close to CNT surface, the unmodified nature of the filler should eliminate the need of explanations involving chemical effects. We thus compiled and analyzed data values of glass transition temperature of CNT/epoxy composites from different articles. The CNT used in these works were unmodified

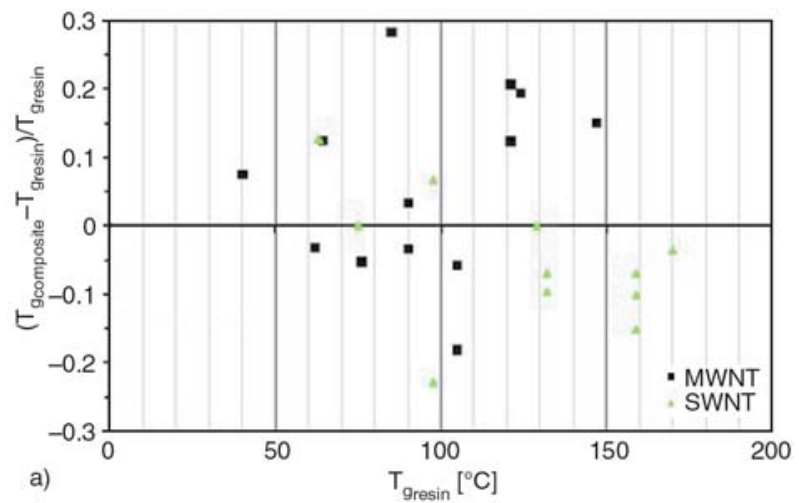

MWNT [8-16] or unmodified SWNT [5, 17-22]. The data relative to preparation method of the composites, glass transition temperature and its measurement method are summarized in Table 1. The relative difference of $T_{g}$ between CNT filled epoxy and the unfilled epoxy as a function of the $T_{g}$ of the unfilled resin or the weight fraction of CNT is plotted respectively in Figure 1a and 1b. In the graphs, the case of SWNT as filler was differentiated from that of MWNT due to the tendency of SWNT to form close-packed bundles with triangular arrangement in the section. It can be noticed that most of the data for SWNT showed a decrease of $T_{g}$ compared to the unfilled resin which may be a consequence of this bundling tendency. Moniruzzaman et al. [21] developed a dispersion method allowing to debundle SWNT and found that $T_{g}$ was unaffected by the presence of SWNT. The data for MWNT was more scattered and no clear trend appeared. The difficulty in analyzing these data resided primarily in the fact that the final cure degree was not provided. Liao et al. [22] showed that the use of solvent of surfactant in the fabrication process can lead to a large decrease of the $T_{g}$. Even after a relatively long process of evaporation (one hour heating +4 hours degassing), Lau et al. [23] reported that remaining residual traces of the solvent (acetone, ethanol and DMF) used in the dispersion process of SWNT in the epoxy resin led to a decrease of the mechanical properties of the SWNT/epoxy composites. They noticed that these detrimental effects increased with the boiling point of the solvent. We plotted again the data for MWNT and made the distinction between experiments in which solvent was used or not in the dispersion process of MWNT in the resin (Figure 2a

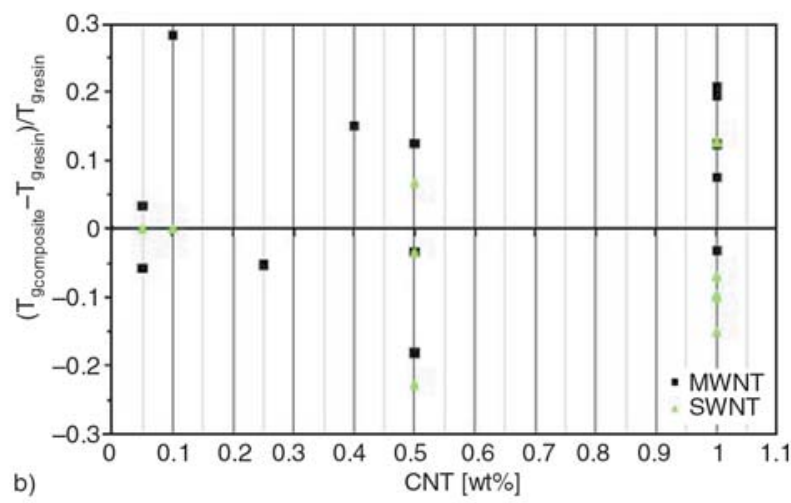

Figure 1. Relative difference of $T_{g}$ of CNT composites compared to unfilled resin as a function of a) $T_{g}$ of the unfilled resin b) CNT weight percentage (data taken from the literature) 
Table 1. Compilation of data from the literature on CNT/epoxy composites (preparation method and glass transition temperature and measurement method, CNT type and aspect ratio when available)

\begin{tabular}{|c|c|c|c|c|c|c|c|}
\hline Reference & $\begin{array}{c}\text { CNT } \\
\text { dispersion process }\end{array}$ & $\begin{array}{c}\mathbf{T}_{\mathrm{g}} \\
\text { Measure } \\
\text { method }\end{array}$ & $\begin{array}{l}\text { wt } \% \\
\text { CNT }\end{array}$ & $\begin{array}{l}\text { CNT } \\
\text { type }\end{array}$ & $\begin{array}{l}\text { CNT aspect } \\
\text { ratio (length/ } \\
\text { diameter) }\end{array}$ & $\begin{array}{c}\mathbf{T}_{\text {gresin }} \\
{\left[{ }^{\circ} \mathbf{C}\right]}\end{array}$ & $\begin{array}{c}\Delta \mathbf{T}= \\
\mathbf{T}_{\text {gcomposite }}- \\
\mathbf{T}_{\text {gresin }^{\circ}\left[{ }^{\circ} \mathbf{C}\right]}\end{array}$ \\
\hline \multirow{3}{*}{ Tao et al. [5] } & \multirow{3}{*}{ Grinding/acetone } & \multirow{3}{*}{ DSC } & \multirow{3}{*}{1.0} & Short SWNT & 417 & \multirow{3}{*}{159.0} & -24.0 \\
\hline & & & & HiPCO SWNT & - & & -11.0 \\
\hline & & & & SWNT/DWNT & - & & -16.0 \\
\hline Zhou et al. [8] & USP & DMA & 0.4 & MWNT & 150 & 147.0 & 22.0 \\
\hline Ganguli et al. [9] & Shear mixing/USP & DMA & 1.0 & MWNT & 625 & 124.0 & 24.0 \\
\hline Ganguli et al. [10] & High speed mixing & DMA & 0.1 & MWNT & 125 & 85.0 & 24.0 \\
\hline \multirow{2}{*}{ Shen et al. [11] } & \multirow{2}{*}{ High speed stirring/USP } & \multirow{2}{*}{ DSC } & \multirow{2}{*}{1.0} & MWNT & 1750 & \multirow{2}{*}{62.0} & -2.0 \\
\hline & & & & MWNT-CONH & - & & -19.0 \\
\hline \multirow[b]{2}{*}{ Tseng et al. [12] } & \multirow[b]{2}{*}{ Shear mixing/USP } & \multirow[b]{2}{*}{ DSC } & \multirow[b]{2}{*}{1.0} & MWNT & - & \multirow[b]{2}{*}{40.0} & 3.0 \\
\hline & & & & $\begin{array}{c}\text { Plasma maleic } \\
\text { anhydride-grafted } \\
\text { MWNT }\end{array}$ & - & & 10.0 \\
\hline \multirow{2}{*}{ Gojny et al. [13] } & \multirow{2}{*}{ USP } & \multirow{2}{*}{ DMA } & \multirow{2}{*}{0.5} & MWNT & 3333 & \multirow{2}{*}{64.5} & 8.0 \\
\hline & & & & MWNT-NH ${ }_{2}$ & 3333 & & 14.0 \\
\hline \multirow{3}{*}{ Shen et al. [14] } & \multirow{3}{*}{ High speed stirring/USP } & \multirow{3}{*}{ DSC } & \multirow{3}{*}{0.25} & MWNT & 1750 & \multirow{3}{*}{76.0} & -4.0 \\
\hline & & & & $\begin{array}{l}\text { Diaminodiphenyl } \\
\text { methane-MWNT }\end{array}$ & - & & -8.0 \\
\hline & & & & $\begin{array}{c}\text { Diaminodicyclohexyl } \\
\text { methane-MWNT }\end{array}$ & - & & 7.0 \\
\hline \multirow{2}{*}{$\begin{array}{l}\text { Hernandez-Perez et } \\
\text { al. }[15]\end{array}$} & USP/ethanol/stirrino & DMA & 10 & MWNT & 50 & 1210 & 15.0 \\
\hline & USP/ethanol/stirring & DIMA & 1.0 & MWNT & 857 & 121.0 & 25.0 \\
\hline & Tip/Bath USP/THF & DMA & 0.5 & MWNT & 85 & & 1.0 \\
\hline & Tip/Bath USP/surfactant & DMA & 0.5 & SWNT & 1000 & 90.0 & 2.0 \\
\hline Fidelus et al. [16] & Tip/Bath USP/THF & DMA & 0.5 & MWNT & 85 & & -15.0 \\
\hline & Tip/Bath USP/surfactant & DMA & 0.5 & SWNT & 1000 & 105.0 & -2.0 \\
\hline & Stirring & & & & & & 9.0 \\
\hline Gong et al. [17] & Stirring/acetone/surfactant & DMA & 1.0 & MWNT & - & 63.0 & 25.0 \\
\hline & & & & SWNT & - & & -6.0 \\
\hline Wang et al. [18] & USP/acetone & DMA & 0.5 & SWNT-NH $_{2}$ & - & 170.0 & -11.0 \\
\hline & & & & SWNT & 500 & & -12.7 \\
\hline & & & & Chopped SWNT & - & & -9.1 \\
\hline Wang et al. [19] & USP/acetone & TMA & 1.0 & Oxidized SWNT & - & 132.0 & -2.4 \\
\hline & & & & $\begin{array}{c}\text { Gum Arabic wrapped } \\
\text { SWNT }\end{array}$ & - & & -21.4 \\
\hline Valentini ot al [201 & USP & DMA & 01 & SWNT & 357 & 750 & 0.0 \\
\hline Valentini et al. $[20]$ & USP & DMA & 0.1 & Butylamine-SWNT & - & 15.0 & 10.0 \\
\hline $\begin{array}{l}\text { Moniruzzaman et al. } \\
\text { [21] }\end{array}$ & $\begin{array}{l}\text { USP/DMF/high shear } \\
\text { mixer }\end{array}$ & DSC & 0.05 & SWNT & - & 129.0 & 0.0 \\
\hline & $\begin{array}{l}\text { Surfactant/acetone/manual } \\
\text { stirring }\end{array}$ & & & & & & -23.6 \\
\hline & Bath/tip USP & & & & & & 6.6 \\
\hline Lian et al [22] & Tip USP/acetone & DMA & 05 & SWNT & - & 976 & -22.2 \\
\hline Liao et al. [LL] & Bath USP/surfactant & DMA & 0.5 & SWNi & - & 91.0 & -22.2 \\
\hline & Tip USP/surfactant & & & & & & -13.4 \\
\hline & $\begin{array}{l}\text { Bath/tip USP/surfactant/ } \\
\text { acetone }\end{array}$ & & & & & & -7.5 \\
\hline
\end{tabular}

(USP: Ultra Sonic Processing)

and $2 \mathrm{~b}$ ). These plots led us to the conjecture that the use of unmodified MWNT as fillers in epoxy may increase or not change the glass transition temperature.

The curing agent type and concentration plays an important role on the final $T_{g}$ of the resin. Curing agent with high functionality provide high $T_{g}$. The $T_{g}$ can also be modified by the curing agent/resin ratio, using a ratio in little excess of the stochiometry gives higher $T_{g}$. The cure behaviour of an epoxy resin can be divided into two stages, a first one in which the reaction is chemically controlled and a 

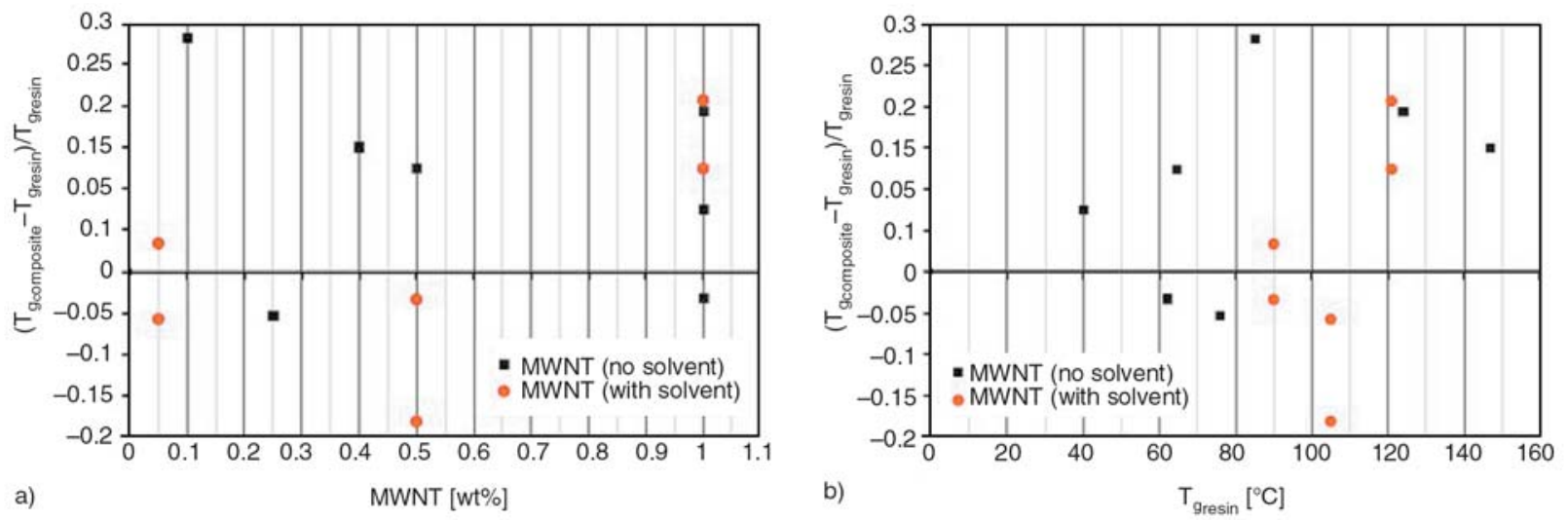

Figure 2. Relative difference of $T_{g}$ of unmodified MWNT composites compared to unfilled resin as a function of a) CNT weight percentage, b) $T_{g}$ of the unfilled resin (data taken from the literature)

second one in which diffusion dominates due to the phenomena of gelation and vitrification. In the early stage, the reaction is initiated by any hydrogen-bond donor molecules which can be moisture, impurities... The reaction is then accelerated by these molecules and the hydroxyl groups formed during the reaction. In the last stage, the viscosity of the mixture increase significantly and the reaction is diffusion-controlled. In the case of epoxy with MWNT, the presence of catalyst particles can initiate the reaction earlier compared to the unfilled resin. The introduction of MWNT in epoxy was found to increase significantly the viscosity of the mixture, up to one of order of magnitude with $1 \mathrm{wt} \%$ MWNT [24]. The improvement of the CNT dispersion state using a mechanical method led to an additional viscosity increase with factor 2 . It is thus expected that the diffusion-controlled stage may be reached earlier in the case of the composites due to the higher viscosity level. The 'advanced' cure degree obtained in the early stage could be counterbalanced by the rapid decrease of the cure in the diffusion-controlled stage. Lower or comparable cure degrees of the composites compared to the resin are expected. Lower cure degree should lead to lower $T_{g}$. In view of their dimensions comparable to polymer chains, CNT could limit their mobility and provide higher $T_{g}$ level. The lower cure degree could be counterbalanced by the restricted mobility of the polymer chains in the vicinity of the CNT. High aspect ratio and good dispersion state of CNT in the epoxy may promote the mobility reduction effect. The presence of CNT could also modify the structure of the final epoxy network which may present a gradient of cross-linking points around CNT. The use of an over-aged hardener [25] gave a rubbery epoxy and remarkable improvement of mechanical and electrical properties with $1 \mathrm{wt} \%$ MWNT. These improvements could be attributed to the loose nature of the rubbery epoxy network which was modified by MWNT. MWNT may have a perturbation effect during the formation of the epoxy network (with more cross-linking points around $\mathrm{CNT}$ ) allowing them to act as an effective reinforcement. A thermal treatment of epoxy close to its $T_{g}$ allows to study the effect of physical aging which allows some rearrangement of the polymer chains. It was found that physical aging limits the strain range over which CNT effectively reinforce the epoxy matrix [26] suggesting possible formation of voids between polymer chains with reduced mobility at the vicinity of CNT and 'free' chains allowed to rearrange through physical aging and sufficiently far from CNT.

The case of functionalized CNT is more complex due to the presence of surface groups that can react with the resin or the hardener, variations of $T_{g}$ are thus expected due to the modified chemical reaction. Miyagawa et al. [27] dispersed fluorinated SWNT in a DGBEF epoxy and observed a decrease of $T_{g}$ that they explained by the non-stoichiometric balance of epoxy to hardener due to fluorine on the surface of SWNT. Even after adjusting the amount of the anhydride hardener, the $T_{g}$ of the composites was always lower than that of the resin. They also observed a slight decrease of the $T_{g}$ when vapour grown carbon fibers (VGCF) were used as fillers in epoxy. They attributed this effect to hydroxyl groups present on the surface of VGCF that can react with hardener. Valentini et at. [20] used butylamine-grafted SWNT in a DGEBA epoxy resin with butylamine as the hardener. They reported an 
increase of the total heat of reaction, a higher final cure degree and a higher glass transition temperature of the functionalized SWNT-based composites compared to the unfilled epoxy. The surface groups reacted with the epoxy resin allowing these improvements.

\section{Conclusions}

In this study, the effect of unmodified MWNT on the cure kinetics and glass transition temperature of an epoxy resin was analyzed on the basis of the literature results. It was found that various authors reported an acceleration effect of CNT. The cure reaction was promoted in its early stage which may be due to the catalyst particles present in the CNT raw material. The effect of CNT on the $T_{g}$ remains unclear. SWNT may lead to a decrease of $T_{g}$ due to their bundling tendency. On the other hand, results reported for MWNT showed an increased or unchanged $T_{g}$ of the composites. The use of solvent can lead to a decrease of $T_{g}$ even after careful evaporation due to residual traces. The present status of the literature does not allow a clarification due to the lack of a study providing essential information such as purity (catalyst particles can affect cure reaction), glass transition temperature along with the corresponding cure degree (to isolate the true potential effect of CNT from curing variations).

\section{Acknowledgements}

Financial support from ARKEMA is appreciated.

\section{References}

[1] Puglia D., Valentini L., Armentano I., Kenny J. M.: Effects of single-walled carbon nanotube incorporation on the cure reaction of epoxy resin and its detection by Raman spectroscopy. Diamond and Related Materials, 12, 827-832 (2003). DOI: 10.1016/S0925-9635(02)00358-8

[2] Valentini L., Armentano I., Puglia D., Kenny J. M.: Dynamics of amine functionalized nanotubes/epoxy composites by dielectric relaxation spectroscopy. Carbon, 42, 323-329 (2003). DOI: 10.1016/j.carbon.2003.10.039
[3] Xie H., Liu B., Yuan Z., Shen J., Cheng R.: Cure kinetics of carbon nanotube/tetrafunctional epoxy nanocomposites by isothermal differential scanning calorimetry. Journal of Polymer Science Part B: Polymer Physics, 42, 3701-3712 (2004).

DOI: $10.1002 /$ polb. 20220

[4] Xie H., Liu B., Sun Q., Yuan Z., Shen J., Cheng R.: Cure kinetic study of carbon nanofibers/epoxy composites by isothermal DSC. Journal of Applied Polymer Science, 96, 329-335 (2005).

DOI: $10.1002 /$ app. 21415

[5] Tao K., Yang S., Grunlan J. C., Kim Y-S., Dang B., Deng Y., Thomas R. L., Wilson B. L., Wei X.: Effects of carbon nanotube fillers on the processes of epoxy resin-based composites. Journal of Applied Polymer Science, 102, 5248-5254 (2006). DOI: $10.1002 / a p p .24773$

[6] Wu J., Chung D. D. L.: Calorimetric study of the effect of carbon fillers on the curing of epoxy. Carbon, 42, 3039-3042 (2004).

DOI: $\underline{10.1016 / j . c a r b o n .2004 .07 .010}$

[7] Bae J., Jang J., Yoon S-H.: Cure behavior of the liquid-crystalline epoxy/carbon nanotube system and the effect of surface treatment of carbon fillers on cure reaction. Macromolecular Chemistry and Physics, 203, 2196-2204 (2002).

[8] Zhou Y., Pervin F., Lewis L., Jeelani S.: Experimental study on the thermal and mechanical properties of multi-walled carbon nanotube-reinforced epoxy. Materials Science and Engineering: A, 452-453, 657664 (2007).

DOI: $10.1016 /$ j.msea.2006.11.066

[9] Ganguli S., Aglan H., Dean D.: Microstructural origin of strength and toughness of epoxy nanocomposites. Journal of Elastomers and Plastics, 37, 19-35 (2005). DOI: $10.1177 / 0095244305045927$

[10] Ganguli S., Aglan H., Dennig P., Irvin G.: Effect of loading and surface modification of MWCNTs on the fracture behaviour of epoxy nanocomposites. Journal of Reinforced Plastics and Composites, 25, 175-188 (2006).

DOI: $\underline{10.1177 / 0731684405056425}$

[11] Shen J., Huang W., Wu L., Hu L., Ye M.: Thermophysical properties of epoxy nanocomposites reinforced with amino-functionalized multi-walled carbon nanotubes. Composites Part A: Applied Science and Manufacturing, 38, 1331-1336 (2007). DOI: 10.1016/j.compositesa.2006.10.012

[12] Tseng C-H., Wang C-C., Chen C-Y.: Functionalizing carbon nanotubes by plasma modification for the preparation of covalent-integrated epoxy composites. Chemistry of Materials, 19, 308-315 (2007). DOI: $10.1021 / \mathrm{cm} 062277 \mathrm{p}$

[13] Gojny F. H., Schulte K.: Functionalisation effect on the thermo-mechanical behaviour of multi-wall carbon nanotube/epoxy-composites. Composites Science and Technology, 64, 2303-2308 (2004). DOI: $10.1016 /$ j.compscitech.2004.01.024 
[14] Shen J., Huang W., Wu L., Hu Y., Ye M.: The reinforcement role of different amino-functionalized multi-walled carbon nanotubes in epoxy nanocomposites. Composites Science and Technology, 67, 30413050 (2007).

DOI: 10.1016/j.compscitech.2007.04.025

[15] Hernández-Pérez A., Avilés F., May-Pat A., ValadezGonzález A., Herrera-Franco P. J., Bartolo-Pérez P.: Effective properties of multiwalled carbon nanotube/ epoxy composites using two different tubes. Composites Science and Technology, 68, 1422-1431 (2008). DOI: 10.1016/j.compscitech.2007.11.001

[16] Fidelus J. D., Wiesel E., Gojny F. H., Schulte K., Wagner H.: Thermo-mechanical properties of randomly oriented carbon/epoxy nanocomposites. Composites Part A: Applied Science and Manufacturing, 36, 1555-1561 (2005).

DOI: 10.1016/j.compositesa.2005.02.006

[17] Gong X., Liu J., Baskaran S., Voise R. D., Young J. S.: Surfactant-assisted processing of carbon nanotube/polymer composites. Chemistry of Materials, 12, 1049-1052 (2000).

DOI: $10.1021 / \mathrm{cm} 9906396$

[18] Wang S., Liang Z., Liu T., Wang B., Zhang C.: Effective amino-functionalization of carbon nanotubes for reinforcing epoxy polymer composites. Nanotechnology, 17, 1551-1557 (2006). DOI: $10.1088 / 0957-4484 / 17 / 6 / 003$

[19] Wang S., Liang Z., Gonnet P., Liao Y-H., Wang B., Zhang C.: Effect of nanotube functionalization on the coefficient of thermal expansion of nanocomposites. Advanced Functional Materials, 17, 87-92 (2007). DOI: $10.1002 / \mathrm{adfm} .200600760$

[20] Valentini L., Puglia D., Carniato F., Boccaleri E., Marchese L., Kenny J. M.: Use of plasma fluorinated single-walled carbon nanotubes for the preparation of nanocomposites with epoxy matrix. Composites Science and Technology, 68, 1008-1014 (2008). DOI: $10.1016 /$ j.compscitech.2007.07.011
[21] Moniruzzaman M., Du F., Romero N., Winey K. I.: Increased flexural modulus and strength in SWNT/ epoxy composites by a new fabrication method. Polymer, 47, 293-298 (2006).

DOI: 10.1016/j.polymer.2005.11.011

[22] Liao Y. H., Marietta-Tondin O., Liang Z., Zhang C., Wang B.: Investigation of the dispersion process of SWNTs/SC-15 epoxy resin nanocomposites. Materials Science and Engineering A, 385, 175-181 (2004). DOI: $10.1016 /$ j.msea.2004.06.031

[23] Lau K-t., Lu M., Lam C-k., Cheung H-y., Sheng F-L., Li H-L.: Thermal and mechanical properties of singlewalled carbon nanotube bundle-reinforced epoxy nanocomposites: The role of solvent for nanotube dispersion. Composites Science and Technology, 65, 719-725 (2005). DOI: $\underline{10.1016 / j . c o m p s c i t e c h .2004 .10 .005 ~}$

[24] Allaoui A., El Bounia N., Courbaron A. C., Derail C.: Enhancement and characterization of carbon nanotubes dispersion in epoxy matrix for structural applications. in 'Proceedings of International Symposium on Aircraft Materials ACMA 2008, Agadir, Morocco' in press (2008).

[25] Allaoui A., Bai S., Cheng H. M., Bai J. B.: Mechanical and electrical properties of a MWNT/epoxy composite. Composites Science and Technology, 62, 19931998 (2002) DOI: $\underline{10.1016 / \mathrm{S} 0266-3538(02) 00129-X}$

[26] Allaoui A., Evesque P., Bai J. B.: Effect of aging on the reinforcement efficiency of carbon nanotubes in epoxy matrix. Journal of Materials Science, 43, 5020 5022 (2008). DOI: $\underline{10.1007 / \mathrm{s} 10853-008-2728-5}$

[27] Miyagawa H., Rich M. J., Drzal L. T.: Thermo-physical properties of epoxy nanocomposites reinforced by carbon nanotubes and vapour grown carbon fibers. Thermochimica Acta, 442, 67-73 (2006). DOI: $10.1016 /$ j.tca.2006.01.016 